\title{
Self-concept Factor Influencing Antenatal Provider Selection: A Qualitative Study from Indonesian Midwives
}

\author{
Dwi Izzati ${ }^{1 *}$ (D), Erni Rosita Dewi ${ }^{1}$, Nur Anisah Rahmawati ${ }^{1}$, Vita Ratna Sari ${ }^{1}$, Amadea Zulfiah Azmi ${ }^{1}$, Budi Prasetyo ${ }^{2}$ \\ ${ }^{1}$ School of Midwifery, Faculty of Medicine Universitas Airlangga, Surabaya, Indonesia; ${ }^{2}$ Department of Obstetrics and \\ Gynecology, Universitas Airlangga, Surabaya, Indonesia
}

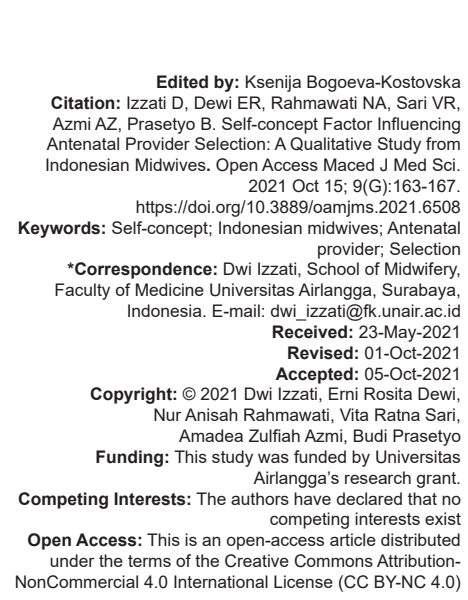

Introduction

The high rate of $\mathrm{C}$-section (CS) procedure is associated with the increase of maternal and neonatal morbidity. The World Health Organization (WHO) determines the CS procedure in developing and developed countries as much as 5-15\%. In Indonesia, the percentage of CS procedure tends to increase about $15.3 \%$ [1]. East Java, known as the second biggest province in Indonesia, has $23.5 \%$ CS procedure in the last 3 years. East Java has 142 obstetricians and 23.572 midwives [2], [3].

Despite the huge number of midwives, the percentage of CS procedure is still not being decreased. This phenomenon is said to be inversely proportional to the philosophy principle of midwives who viewed a physiological pregnancy. The different philosophy of care between midwives and obstetricians influences a maternal health service. Midwives deliver a holistic physiological approach, while obstetricians implement a medical approach and a technocratic model. Different perspectives in interpreting professional philosophies may impact the choices of antenatal care (ANC) providers for midwives themselves [4].

Perspective of midwives, while giving ANC, is influenced by characteristics that have evolved differently according to local or regional cultural, social traditions, and knowledge [5]. As revealed by prior research, Indonesian midwives who live in Bali have a tendency to lead concept of medicalization; therefore, they thought at risk factors [6]. This study aims to determine the self-concept of Indonesian midwives in interpreting professional philosophy regarding the decision-making of the antenatal provider during pregnancies.

\section{Materials and Methods}

The research design used is descriptive qualitative research with a phenomenological approach. The research participants were 15 midwives in Surabaya, Indonesia, who were taken using the purposive sampling methods. The inclusion criteria 
of research participants were midwives who were still active in providing midwifery services in both primary and secondary health-care facilities and had pregnancy experience. Meanwhile, the exclusion criteria included midwives who refused to be respondents.

The research variable was the midwife's perspective in choosing ANC. Perspective refers to a main factor which includes self-concept. The initial data used are secondary data, obtained from the archive of the number of active midwives in the city of Surabaya. The primary data obtained from filling in the general data of respondents through a Google form. The general data of respondents contain the identity of the respondent, themselves. Each general data contains a name, age, last education, and place of work. The specific questions are about obstetric status and training of the respondent's data.

Furthermore, this research carried out with an in-depth interview process according to the schedule agreed upon by the respondent. Interviews were conducted online using the Zoom meeting application, which lasted 60-90 min. The instruments used in data collection included a recording device, a field note, and a list of interview questions.

Writing respondent data use a predetermined code to maintain the privacy of respondents. The code used is R1-R15. The validity of the data was obtained by paying attention to the principles of naturalistic, interpretive, inductive, context-based, and reflexive. Data were analyzed using the thematic analysis techniques. The results of the conclusions are descriptive of the process of drawing conclusions carried out by the stages of open coding, axial coding, and selective coding.

\section{Ethical considerations}

This research has been declared worthy of ethics by the Ethics Committee of the Faculty of Medicine, Universitas Airlangga with the number: 300/EC/KEPK/FKUA/2020. For each interview, the researcher explained the field and aim of the study and, if the participant was satisfied and they signed the consent form. The researcher committed to stop recording the interview if the participants did not wish to continue the interview.

\section{Results}

The detail data of respondents are shown in Table 1.

In self-concept factor, the questions include the length of study, history of training, the of authority of midwife, the ideal ANC system, history of
Table 1: Characteristics of respondent

\begin{tabular}{lll}
\hline Category & Total & Percentages \\
\hline Age & 12 & \\
$\leq 35$ & 3 & 80 \\
$\quad>35$ & & 20 \\
Level of education & 11 & 73.30 \\
$\quad$ Diploma & 3 & 20 \\
$\quad$ Bachelor & 1 & 6.70 \\
$\quad$ Master & 7 & 46.70 \\
Level of health facilities & 8 & 53.30 \\
$\quad$ Primary health facilities & & \\
$\quad$ Secondary health facilities & 7 & 46.70 \\
Parity & 8 & 53.30 \\
$\quad$ Primipara & & 53.30 \\
$\quad$ Multipara & 8 & 46.70 \\
History of obstetric status & 7 & 100 \\
$\quad$ Without complication & & 0 \\
$\quad$ Without complication & 15 & \\
Participation in Midwifery training & 0 & \\
$\quad$ Yes & & \\
$\quad$ No & &
\end{tabular}

pregnancy/childbirth/after birth, philosophy of normality and risk, family decision-making and expectations, and the ANC provided by midwives.

The education taken by the respondents varied from diploma to master program. The average respondent took midwifery education for 3-8 years. Most of the training that the respondents participated which tends to be required by the workplace institutions such as APN (normal childbirth care), PPGDON (emergency obstetric-neonatal training), Contraceptive Technology Update, and Basic Life Support (BLS). Meanwhile, complementary midwifery training is less attractive. This opinion was represented by R15 "2011, I participated in APN and CTU training because of my obligations on campus. The diploma certificate will not give if they do not participate in the training. 2012 joined the BLS training because of compulsory work training in the hospital. In 2014, it was funded by the Surabaya City Health Office to participate in PPGDON. I have never participated in complementary midwifery training."

Most respondents already understood the authority of midwives. However, the implementation is depended on the level of health services at where they work. In primary health care, the respondent stated that midwives have provided services following the authority of midwives. The following is a statement from respondent R6 "The midwife's area of authority includes ANC, INC, PNC, newborn care, and family planning. However, in reproductive health, we can only give counseling and mostly refer to if the cases are more complex and complicated." Another opinion was conveyed by R1 "Here, ANC is quite good and free that underregulated authority of the midwife. Assisting in childbirth and other care has been supported by healing, although there are still boundaries for pathological areas."

In the secondary level, the authority of midwives is limited due to different regulations in each agency and required to work with multiple professions. R11 stated "The midwife's authority in my workplace is divided into several levels. Not all powers and duties of a midwife can be carried out independently. Assignment of skills in stages depending on the length of services 
experience and hospital credentials. The authority given to me includes nursing practices, physiological obstetric measures, and health education. Another opinion was given by R3 "We cannot provide medication. We can only provide supportive care such as nutrition, health education and personal hygiene, because the doctors have main responsibility of the patient. Midwives have more roles in primary than secondary level. Although the secondary level still needs midwives, their role will be much more significant at the primary level."

All respondents assume that the ANC system in Indonesia is ideal. Midwifery services provided have referred to national and international guidelines. This was stated by R15 "It is ideal. We have provided services according to the integrated ANC guidelines, including laboratory examinations." Another opinion was conveyed by R12 "In my experience working in hospitals each practice based on the standards." The referral system has been demonstrated in Indonesia. This is in line with R10's opinion, "The ANC system has already well-managed by collaborating with health center, hospital, and private midwife practice." However, some respondents thought that ANC providers, especially midwives, needed to improve their quality. The view was given by R1 The system is ideal yet still vary. Every midwife is skillful, but the limitation of time services affects midwives' quality. "Another opinion was conveyed by $\mathrm{R} 9$ who stated, "It continues to develop, but the problem of patience has not yet appeared, and midwives should be able to provide comprehensive care."

Respondents who chose midwife as provider thought that their pregnancy was a physiological one. R8 said, "For the sake of convenience, my pregnancy is checked by midwives colleagues, so are my friends. While ultrasound and laboratory performed by obstetrician at the health center." Respondents who had complications or a bad obstetric history in pregnancy chose to check the ob-gyn's ANC service. According to R5 "My pregnancy was unique and challenging. Two times abortions made me even more careful about pregnancy planning. This caused me to be routine at obstetrician from the start of preparation." However, even though some respondents had pregnancy check-ups at the obgyn, they preferred birth attendants in midwife. According to R12 "I had a miscarriage. This second pregnancy went smoothly even though I had spotting during pregnancy. I sometimes mix it with the practicing midwife, health center, and the obstetricians where I work for pregnancy control. There was a hemorrhoid, but after the consultation, the labor can be normal. Hence, for the delivery, I chose the midwife near my house."

All respondents stated that the antenatal services provided were quite good. One respondent stated that she never got ANC by a midwife but she gave a positive view. She believes that midwives have experienced a significant increase in service quality compared to before. Several respondents stated the advantages of midwife's antenatal services, namely clinical decision-making based on the patient's real condition, according to standard service protocols, educative in counseling, and being able to provide comfort services. R14 respondent explains that midwives have followed the minimum standard of ANC, "It is following existing guidelines, such as by the 10T (ANC standard by Indonesian government), complete screening, blood tests, and filling of the appropriate MCH Handbook." Then to R15 stated, "I feel satisfied with the ANC services provided by the midwives at this time, especially because I know what the ability of the midwife who examined me was like. I like the patience, thoroughness, and personality qualities of the midwives themselves."

However, most respondents also stated the philosophy of risk of pregnancy. They believe that even if the pregnancy is normal, it can be a risky pregnancy. R9's opinion regarding the philosophy of risk is as follows "Pregnancy can be a risk even though sometimes there are no signs. Due to limited tools and authority, midwives are sometimes not good enough to check ANC." In addition, according to R5, "Pregnancies that look normal must be prepared properly because there are times when complications arise. Everything natural is safer in all esteem. However, there are times when it does have to be done by cesarean section. It must occur to minimize the risk further than enforced normalcy."

In the decision-making process, all respondents stated that they could play an active role in making choices, especially in selecting ANC and delivery providers. In the process, the respondents discussed with their husbands, parents, and in-laws. Furthermore, they are considered to have a better understanding of pregnancy because they work as midwives. As the narrative from R5 follows: "Decision-making is done by myself, but the discussion is with my husband because my husband thinks I have the capacity in this matter."

\section{Discussion}

In the education undertaken, the respondent explained that the respondent had various educational backgrounds, even starting from the School of Nursing (SPK), equivalent to high school to the master's level. This is because the midwifery education system in Indonesia has undergone many changes over the last few decades. The types of training that the respondents participated in were almost dominated by certified training. There are no respondents who have attended complimentary midwifery training such as hypnobirthing, gentle prenatal yoga, birth acupressure, etc., which mostly promotes natural birth. The knowledge and 
understanding obtained from formal education and training can influence perceptions on choosing an antenatal provider, and the form of services provided when becoming a midwife because through continuous education and training is the primary strategy for improving the personal quality of midwives in providing midwifery care [7].

Respondents fully understand the limits of a midwife's authority in the physiological domain that focuses on health promotion and prevention efforts. They consider that pregnancy, childbirth, and childbirth are normal processes so that with proper preparation and monitoring, everything can run naturally [8]. Useful findings were also obtained from responses to fairly good antenatal services provided by midwives. In the implementation of their pregnancies, all respondents had used antenatal services provided by midwives, which were mostly used as a place of choice for delivery, except for R7 who stated that they had never seen a midwife, but she stated positive comments on midwife services. Some state their pregnancy is normal and they are more comfortable being examined by a midwife. This is in line with the findings of a study conducted by [9] which states that the quality of service and place of care can be the advantage of midwives in caring for mother who gave birth. In this case, a mother will likely have the optimal experience of childbirth. However, to ensure normal conditions and relieve anxiety about their pregnancy, they need special ultrasound examinations for a more detailed examination [10]. Whereas in the regulation of USG services in Indonesia (PMK No. 97 on Pregnancy Health Services and PMK No. 28 on Licensing and Implementation of Midwifery Practices), obstetricians can only do so, requiring them to continue to check pregnancy with obstetricians.

Meanwhile, the International Confederation of Midwives (ICM) carries out regular updates on Essential Competencies for Basic Midwifery Practice, one of which is competence for pregnancy ultrasound. In a systematic study conducted by [11] found that prenatal ultrasonography was supported as an advanced $(76.6 \%)$ or country-specific $(18.8 \%)$ skills that midwives could acquire, to promote more comprehensive global access for pregnant women. The stated goals of using basic ultrasound examination (such as placental localization and calculation of amniotic fluid volume) are in line with the goals of essential pregnancy services cited by the $\mathrm{WHO}$ in its recommendations. Furthermore, the reports of USG services by midwives were found in several developed countries such as Norway, UK, and Japan [12]. Furthermore, in research reports in developing countries such as Sudan, village midwives could reliably diagnose the presence of pregnancy, viability, twins, and missed abortion after a short training. They could accurately estimate GA in the first trimester and determine the location of the placenta. USG would be useful when used by village midwives to select patients for referral to specialist care in complicated pregnancy cases [13]. Hence, that ANC for low-risk pregnancies with adequate risk screening can be covered by midwife services alone.

The self-concept of these respondents also affects antenatal provider' choice, especially in the decision-making process. All respondents and their closest people, such as husbands, parents, and parentsin-law, appreciate their ability in making decisions about ANC because of their capacity as midwives. They claim to be empowered, respect their opinion and expectations, where the autonomy in decision-making significantly affects a midwife's self-understanding [14].

In the current working conditions, both respondents who work in primary and secondary facilities stated that they all enjoy their work because it has become their profession as a midwife. Job satisfaction is received when midwives feel that they provide good service to women, have positive interactions with women in their care and see women happy [15]. Different things were revealed related to agency policies and their choice, which resulted in midwives having other roles outside their jobs. Midwives in independent environments have significant autonomy in carrying out their work. Work autonomy in health-care agencies linked across professions allows a different application from the independent practice of midwives [16]. This has resulted in different views regarding the professional development of midwives. Most midwives focused on midwife's counseling and communication skills that needed to be improved. Effective communication between maternity care providers and women in labor, using simple and culturally acceptable methods, is recommended [17]. This counseling capability is essential because midwifery plays an "important" role, and when provided by educated, trained, regulated, licensed midwives it is associated with improved quality of care and rapid and sustained reduction in maternal and newborn (WHO) mortality rates. Motivations for midwives to increase their role in their sphere of practice include implementing midwifery education programs following international standards, prioritizing and enforcing policies regarding the rewards of their work, engaging midwifery associations in policy and planning regarding the midwifery workforce, and ensuring that the work environment for midwives is safe and wellequipped [18].

\section{Conclusion}

The most significant factors that play an essential role in influencing midwives to decide the antenatal provider are self-concept. This research finds a limit understanding of the philosophy of midwifery care which defines the midwives' decision-making in receiving $A N C$ still low. The novelty of minimum 
regulations and authority toward Indonesian midwives in doing USG as early detection, makes most respondents are not willing to do ANC in midwives.

\section{Acknowledgments}

The researchers thank all midwives who participated in this study.

\section{References}

1. Central Bureau of Statistics. SDKI 2012 Demographic and Health Survey 2012. Kementrian Kesehatan Rl; 2013.

2. Badan BPSDM Kemenkes RI. Informasi SDM Kesehatan; 2020.

3. Dinas Kesehatan Jawa Timur. Profil Kesehatan Jawa Timur 2018; 2019.

4. Walsh D. Practice Intrapartum Case. United States: Blackwell Publishing Ltd.; 2010.

5. Maramis. IImu Perilaku dalam Pelayanan Kesehatan Surabaya. Surabaya: Airlangga University Press; 2010.

6. Indrawati NM. Persepsi Bidan Yang Bersuku Bali Dalam Memilih Antenatal Care (ANC) Di Kota Denpasar. Surabaya, Indonesia: Universitas Airlangga; 2019.

7. Goemaes R, Beeckman D, Verhaeghe S, Van HeckeA. Sustaining the quality of midwifery practice in Belgium: Challenges and opportunities for advanced midwife practitioners. Midwifery. 2020;89:102792. http://doi.org/10.1016/j.midw.2020.102792 PMid:32653612

8. Carlin A, Alfirevic Z. Physiological changes of pregnancy and monitoring. Best Pract Res Clin Obstet Gynaecol. 2008;22(5):801-23. http://doi.org/10.1016/j.bpobgyn.2008.06.005 PMid: 18760680

9. Borrelli SE, Spiby H, Walsh D. The kaleidoscopic midwife: A conceptual metaphor illustrating first-time mothers' perspectives of a good midwife during childbirth. A grounded theory study. Midwifery. 2016;39:103-11. http://doi.org/10.1016/j.

\section{midw.2016.05.008}

PMid:27321727

10. Nicoloro-SantaBarbara J, Rosenthal L, Auerbach MV, Kocis CC, Lobel M. Patient-provider communication, maternal anxiety, and self-care in pregnancy. Soc Sci Med. 2017;190:133-40. http:// doi.org/10.1016/j.socscimed.2017.08.011 PMid:28863336

11. Fullerton J, Butler M, Aman C, Reid T. Global competencies for midwives: Externalcephalicversion; ultrasonography, and tobacco cessation intervention. Women Birth. 2019;32(3):e413-20. https:// doi.org/10.1016/j.wombi.2018.08.166

12. Fagerli TA, Mogren I, Adolfsson A, Edvardsson K, Åhman A Holmlund S, et al. Midwives' and obstetricians' views on appropriate obstetric sonography in Norway. Sex Reprod Healthc. 2018;2018:1-5. https://doi.org/10.1016/j.srhc.2017.12.006 PMid:29804752

13. Yusuf AY, Awadalla KE. P17. 02: Ultrasound in early pregnancy by village midwives in Sudan. Ultrasound Obstet Gynecol. 2018;52:181

14. Toe LP, Samuelsen H. Balancing professional autonomy and authority at the margins of a fragile state: Front-line health workers' experiences in Burkina Faso. Glob Public Health. 2021;16(7):1099-110. https://doi.org/10.1080/17441692.2020.1 825768

PMid:33028153

15. Sullivan K, Lock L, Homer CS. Factors that contribute to midwives staying in midwifery: A study in one area health service in New South Wales, Australia. Midwifery. 2011;27(3):331-5. https://doi.org/10.1016/j.midw.2011.01.007 PMid:21458894

16. Clemons JH, Gilkison A, Mharapara TL, Dixon L, McAra-Couper J. Midwifery job autonomy in New Zealand: I do it all the time. Women Birth. 2021;34(1):30-7.

17. World Health Organization. Preconception-PregnancyChildbirth-and-Postpartum-Care-During-Childbirth whoRecommendation Effective-Communication between-Maternity Care Providers-and Women Labour. Geneva: World Health Organization; 2020.

18. Bogren M, Grahn M, Kaboru BB, Berg M. Midwives' challenges and factors that motivate them to remain in their workplace in the Democratic Republic of Congo an interview study. Hum Resour Health. 2020;18(1):165. https://doi.org/10.1186/ s12960-020-00510-x

PMid:32943067 